\title{
A ARTE CONTEMPORÂNEA E A FALTA DE INTERESSE
}

\section{CONTEMPORARY ART AND THE LACK OF INTEREST}

\author{
ALBUQUERQUE, Fellipe Eloy Teixeira
}

\begin{abstract}
RESUMO: Atualmente a arte está chegando a um determinado ponto que sua complexidade de interpretação, ou confunde completamente ou exclui os observadores simplistas do seu circuito. Geralmente esses espectadores ainda mantêm um padrão estético forte, ligado a narrativa mestra da representação mimética, talvez por conta disso sintam dificuldades em apreciar uma obra de arte conceitual. Se não bastasse a limitação de grande parte do público, a arte contemporânea ainda precisa lidar consigo mesma, com questões financeiras e de mercado além das novas possibilidades de espaços para exposição. Esse texto discutirá sobre os diferentes segmentos da arte que sofreram recentemente pelo desinteresse evidente, o objetivo é desvendar se isso é apenas mais um reflexo de nossa sociedade, ou se acontece propositalmente, indicando um novo caminho para as artes.
\end{abstract}

PALAVRAS-CHAVE: Arte, desinteresse, sociedade.

\begin{abstract}
Currently the art is coming to a point that the complexity of interpretation, or confused or completely excludes simplistic observers of your circuit. Generally these viewers still maintain a strong aesthetic standard, on the master narrative of mimetic representation, perhaps because of that feel difficult to appreciate a work of conceptual art. Not only that the limitation of much of the public, contemporary art has yet to deal with herself, with financial issues and market as well as new possibilities for exhibition spaces. This paper discusses about the different segments of art that recently suffered by the apparent lack of interest, the goal is to discover if this is just another reflection of our society, or if it happens on purpose, indicating a new path for the arts.
\end{abstract}

KEYWORDS: Art, disinterest, society. 


\section{Desinteresse cultural}

Em um país marcado durante muitos anos pela alta taxa de analfabetismo, baixo desenvolvimento humano e de evidente desigualdade econômica, não é surpresa para ninguém que haja um grande desinteresse artístico em todas as camadas da população. Pensando nesse contraste cultural, que assola negativamente a todos nós, esse texto organizado em forma de artigo científico buscará compreender como no sistema das artes, algo que envolva o mercado, espectadores, instituições, espaços e alguns dos mediadores pode sentir os efeitos dessa falta de interesse, sobretudo, no que diz respeito à arte contemporânea.

Arte que chegou a um determinado ponto onde sua complexidade de interpretação, ou confunde completamente ou exclui os observadores simplistas do seu circuito. Geralmente esses observadores ainda mantêm um padrão estético forte, ligado a narrativa mestra da representação mimética. A frase de um dos grafiteiros Os Gêmeos: “- Aquilo que não se vê não exclui o que se pode ver", mencionada em trecho do filme Cidade Cinza (MESQUITA; VALIENGO, 2013), exemplifica nossa problemática sobre o interesse pelo público pela arte contemporânea, enquanto o filme em si traz importantes contribuições sobre a ação política, outras questões circundam o espectador.
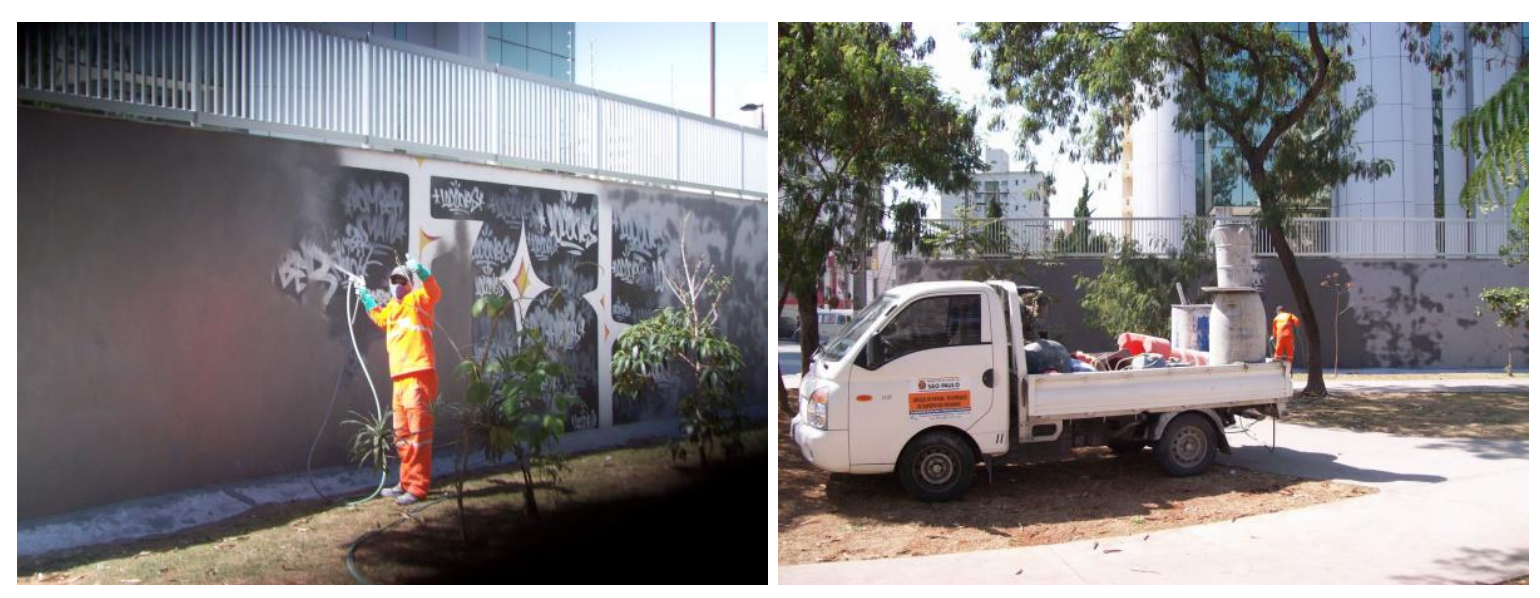

Ilustração 1: Funcionário da prefeitura cobrindo mural de Graffiti. Fonte: No quintal de casa.

O filme Cidade cinza faz parte de um grupo de produções cinematográficas recentes que trazem à tona a discussão sobre o que pode ser considerado arte para o contexto contemporâneo. Nesse documentário específico nos é mostrado o despreparo dos 
poderes constituídos em julgar e interpretar as manifestações artísticas contemporâneas. Por conta da aprovação de uma lei conhecida como "Cidade Limpa", funcionáriosdesinformados- da prefeitura de São Paulo apagaram um mural na alça de acesso à Avenida 23 de maio. Só depois de muita pressão por parte da mídia e organizações internacionais, foi que a prefeitura reconheceu o erro e autorizou à re-pintura do painel, sob financiamento privado.

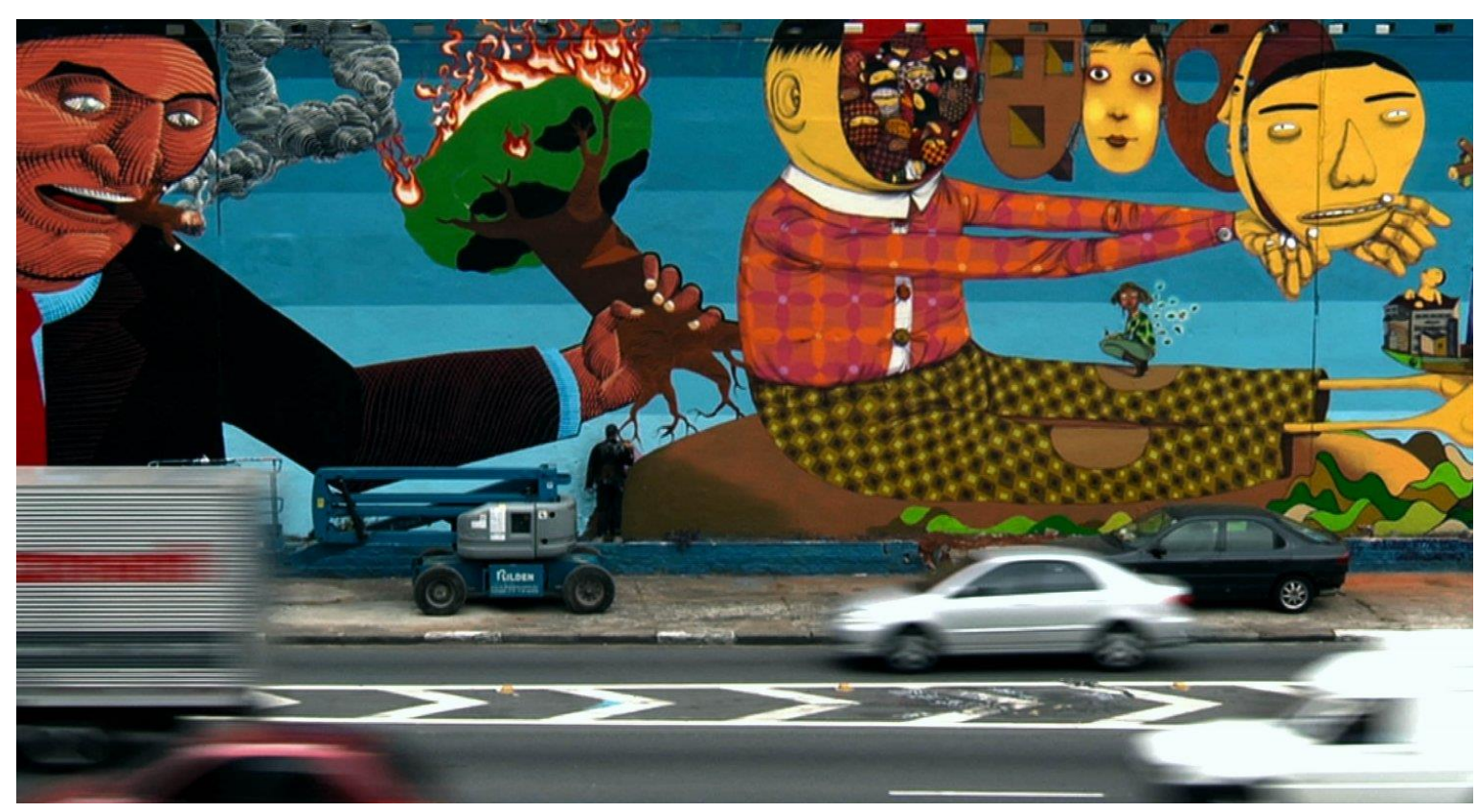

Ilustração 2: Detalhe da recuperação da mural na alça de acesso à Avenida 23 de maio. Fonte: Divulgação/Blog do Sadovsky.

O exemplo de um filme para expor o desinteresse de muitos espectadores brasileiros sobre a arte contemporânea é proposital, afinal segundo os dados da pesquisa: "Públicos de Cultura: hábitos e demandas", organizados pelo SESC (SESC-SERGIPE, 2015) com apoio da Fundação Perseu Abramo, divulgados em abril de 2014, o brasileiro prefere assistir um filme a ler um livro sobre o mesmo assunto. Além desse dado a pesquisa ainda faz menção ao fato da maioria dos brasileiros consultados reservarem menos de $20 \%$ dos dias úteis do ano para qualquer tipo de prática cultural.

Para a questão da aceitação do espectador pela arte contemporânea, ainda temos o exemplo de outro filme: Lixo extraordinário (WALKER, 2009) que traz em trecho- entre a altura de 1:18h e 1:20h do filme- mostra uma conversa entre Vik Muniz e Tião Santos sobre o gosto, após ter sido levado para uma casa de leilões, onde ouviu explicações sobre as diferentes obras de arte contemporânea expostas pelos corredores do recinto. Nessa 


\section{1 jangada}

cena, o então catador e líder da ACAMJG- Associação dos Catadores do Aterro Metropolitano de Jardim Gramacho, foi indagado pelo artista plástico sobre o que ele havia achado das obras, Tião em primeiro momento reconheceu sua dificuldade em entender os propósitos das representações abstratas, mas admitiu que após ter ouvido as explicações e entender do que se tratava, começou a gostar. Vik Muniz completa a sentença com a frase: “- De repente é falta de conhecimento que nos faz não gostar das coisas?". Era justamente nesse ponto que precisávamos chegar para começar a discutir sobre a complexidade da arte contemporânea.

\section{Qual o problema com a Arte Contemporânea?}

Consideremos o fato de que o desinteresse- de alguns- está relacionado com a falta de conhecimento sobre os parâmetros teóricos e conceituais por traz de uma obra de arte contemporânea. Sobre essa perspectiva escreveu Julian Bell, ressaltando o seguinte pressuposto: “O que está perto demais embaça a visão”. O autor assim como muitos outros tenta trazer para o leitor uma retrospectiva daquilo que chamamos de arte contemporânea, mas de maneira cautelosa, afinal, "tudo aqui está em plena atividade." (BELL, 2008, p.451).

Para Arthur Danto, o problema da interpretação da arte contemporânea não se encontra apenas na proximidade e no movimento dela, mas em sua narrativa. $\mathrm{O}$ autor estadunidense enfatiza a morte da arte como a morte de uma narrativa mestra que a todos englobava e os levavam a encontrar o seu lugar definitivo, para ele a arte que está sendo feita caminha para além da história, uma arte pós-histórica, por conta disso uma arte não explicável por meios tradicionais.

A francesa Anne Cauquelin trabalha o mesmo tema a partir da ideia de regimes, segundo ela enquanto a arte moderna estava inserida no regime do consumo, a arte contemporânea faz uso do regime da comunicação para se manter no cenário cultural. A arte atual faz usos de "mecanismos induzidos pelo regime da comunicação em vigor na sociedade contemporânea" (CAUQUELIN, 2010, p. 39). Tais mecanismos são identificados a partir de seus efeitos que podem ser causados pela ideologia dominante e/ou pelos domínios particulares. Os principais efeitos assimilados pela arte contemporânea são a organização em rede, o looping, a redundância, a denominação e a simulação. Cada um com sua particularidade específica. 
A organização em rede e o efeito looping aos quais Cauquelin se refere, estão intimamente ligados. Para a comunicação a rede é uma estrutura interligada com inúmeros pontos de acesso e o looping é a constante reativação de conexões entre esses pontos, ou seja, o looping é a impossibilidade de "sair da rede depois de nos termos ligados" (CAUQUELIN, 2010, p. 42). A redundância é a consequência desse círculo vicioso, é o que "assegura, com efeito, a manutenção da rede, mas também a condena ao desgaste por saturação" (CAUQUELIN, 2010, p. 42). A denominação por sua vez, corresponde à necessidade de demarcar uma informação, serve para efetuar "uma classificação nas várias entradas interligadas, ou seja, uma hierarquia por níveis de complexidade" (CAUQUELIN, 2010, p. 43). Já a concepção da simulação da realidade, sofre influência da linguagem usada para entender o mundo, "são novas ferramentas para a compreensão da realidade que nos rodeiam" (CAUQUELIN, 2010, p. 44). Segunda a autora, todas estas transformações estão aplicadas ao mercado de arte, norteando um novo modo de fazer artístico.

Para Giulio Carlo Argan, a questão principal para compreender a arte contemporânea está na crise à qual ela se insere. Em seu livro mais célebre: Arte moderna (ARGAN, 1992), Argan destina seu último capítulo para discutir a crise da arte como ciência, partindo da mudança do centro cultura pós-Segunda-Guerra, que desloca para Nova Iorque o ponto de referência para os outros centros de aspectos secundários, como Paris, Tóquio, São Paulo, Veneza e Berlim. “A arte dos Estados Unidos atinge ao mesmo tempo uma posição de autonomia e de hegemonia”, com características próprias, sendo uma delas o melhor exemplo para entender a arte contemporânea: "a ausência de qualquer inibição em face de todas as tradições” (ARGAN, 1992, p. 507). Nesse sentido a arte contemporânea seria uma reação causada pelo modelo de sociedade oferecido pelo padrão de vida estadunidense.

Em outra publicação: História da Arte como história da cidade (ARGAN, 2014) o autor também recorre à metáfora da crise, primeiro para falar sobre o paradigma que cerca o urbanismo como prática artística ou cientifica. Para essa questão- que pode ser associada à ideia da crise como ciência- o autor demonstra total apatia, isso por não ver sentido algum nessa discussão. "Não tem sentido, porque a distinção e a oposição das categorias da arte e da ciência já não nos interessa. Pertence a um esquematismo cultural superado, não serve mais para esclarecer, mas apenas para confundir as ideias" (ARGAN, 2014, p. 211). Assim como o urbanismo, são as novas disciplinas- surgidas a partir de algum 




momento da segunda metade do século XX- que fazendo uso de materiais da cultura precedente se distinguem de qualquer outra linguagem artística, principalmente pela forma de elaboração dos seus conteúdos, como são colocadas em relação dialética entre si, como essas maneiras de fazer dão lugares para as resultantes,

\begin{abstract}
A resultante não é um quadro estatístico nem a representação sintética de uma situação social de fato; é um programa, um plano, um projeto tendo em vista a mudança de uma situação de fato reconhecia como insatisfatória. Trata-se, porém de saber o que e com que e com que fim se programa, se planeja, se projeta. (ARGAN, 2014, pp. 211-212)
\end{abstract}

Um teórico brasileiro discute sobre os métodos adotados por Argan e Danto para se referirem a tal crise/momento histórico da arte. Lorenzo Mammì (2012) aproveita a referência- que não conseguimos consultar- "A crise da crítica e a crise da arte”, último capitulo do livro "Arte e crítica da arte", de Argan e o mesmo livro que consultamos de Arthur Danto: "Após o fim da arte" (2006), além do "O fim da história da arte" (2006), de Hans Belting. Ele enxerga algumas fragilidades na tese de Danto, no que diz respeito a filosofia, que precisaria “da arte enquanto atividade atualmente presente, mas não necessariamente de obras de artes específicas: para chegar a uma definição genérica de arte” (MAMMÌ, 2012, p. 21) o que torna dispensável a atribuição de valor, resultando numa crítica de arte sem arte.

Argan é visto por Lorenzo, como um historicista de fato, enquanto Danto um filósofo da arte que discute História da Arte, por conta disso Argan estaria usando mecanismos mais adequados para análise do problema, reconhecendo o lugar, a colocação e o valor de determinada obra na cultura e no contexto histórico. A partir dessa perspectiva reconhece-se o fato de um objeto ser considerado obra de arte "apenas na mediada em que encarna um conteúdo histórico determinado num valor estético que de alguma maneira o transcenda, fixando-o num conteúdo universal" (MAMMÌ, 2012, p. 21). Sendo assim, considerar o fim da história da arte é ao mesmo tempo reconhecer o fim da própria arte e da crítica.

Outro nome importante para pensar em História da Arte e o problema da arte contemporânea é Ernest H. Gombrich, com seu livro A História da Arte (2013) o autor

\footnotetext{
${ }^{1}$ Publicação de 1984.

Jangada | nr. 10, jul/dez, 2017 | ISSN 2317-4722 - 109 |P ág i n a
} 


\section{1 jangada}

esteve presente em várias listas de referências bibliográficas nos cursos de formação na área das Ciências Humanas e Artes. O fato é que, originalmente esse livro foi escrito pouco depois da Segunda Guerra Mundial, sendo lançado pela primeira vez em 1950. Portanto, na mesma época que a maioria dos artistas e obras responsáveis pela nova ordem da representação artística estava surgindo. A medida do tempo, o autor percebeu a necessidade de agregar outro capítulo para sua obra literária. Sendo na sua $11^{\text {a }}$ edição acrescidas a maior parte dos escritos agora consultados nessa última edição, capítulo esse hoje com outro título.

No começo desse capítulo, Gombrich ressalta a mesma posição adota por Julian Bell, “a história dos artistas só pode ser contada quando já ficaram claras, passado um certo tempo, que influências seu trabalho teve sobre os demais e qual foi sua contribuição para a história da arte como tal” (GOMBRICH, 2013, p. 466). Mas em outro ponto adiante, ele uso a ideia da "tradição do novo" desenvolvida pelo crítico Harold Rosenberg para comparar a atitude adotada pelos artistas contemporâneos, "a ideia de que os artistas devem estar na vanguarda do progresso" (GOMBRICH, 2013, p. 485).

O que se espera com isso não é confundir o leitor com uma lista de teóricos e críticos que escreveram sobre a complexidade interpretativa por traz da arte contemporânea. Ao contrário o intuito maior é expor essas múltiplas vertentes que tentam interpretar a partir de referenciais distintos, um fenômeno recente, que ainda não entrou em consenso. Nisso tudo existe apenas uma resposta, muito vaga e imprecisa, e que a maioria dos autores reconhece como certa: "a arte contemporânea seria arte produzida por nossos contemporâneos" (DANTO, 2006, p. 12) - que também são difíceis de entender.

\section{Desinteresse por parte do espectador}

O fato de ser amplamente discutido e com vertentes que podem ser associadas a outras áreas do conhecimento, já seria motivo suficiente para que o interesse pela arte contemporânea estivesse entre as principais pautas de grupos de pesquisas e rodas de conversas entre estudantes e professores. O que acontece, porém, é o contrário, aparentemente o gosto estético a qual a maioria dos espectadores culturalmente ativos prefere conviver diariamente é aquele que trás traços da arte romântica (ALBUQUERQUE, 2014, p. 06). 




Considerando a metodologia de Vik Muniz, bastaria apenas entender a arte contemporânea e a ideia por traz de cada atividade do artista, para que passássemos a gostar tanto desta arte ou de tal artista. Essa tarefa, no entanto é muito complicada, como vimos não existe apenas uma interpretação legítima que possamos nos apoiar sem que consideremos outras tantas tão convincentes quanto. $\mathrm{O}$ professor e pesquisador estadunidense Terry Barrett (2014) tenta a partir da crítica da arte, ajudar a nós leitores e espectadores a entender o contemporâneo. Na parte que Barrett destina para a Teoria e Crítica de Arte (BARRETT, 2014, p. 30-65), ele analisa a crítica da arte atual relacionando-a com discussões em torno das novas teorias pós-modernistas ${ }^{2}$. Sendo a primeira dessas teorias a ser discutida, àquela que tenta fazer uma distinção inteligível entre modernidade e pós-modernidade.

"Estamos em uma época que muitos chamam de Pós-Modernidade. A PósModernidade, de acordo com algumas pessoas já substituiu a Modernidade, mas segundo outros elas convivem lado a lado” (BARRETT, 2014, p. 30). Nisso Arthur Danto também concorda, pois afinal “da mesma forma que 'moderno' não é simplesmente um conceito temporal, significando, digamos, o' mais recente', tampouco 'contemporâneo' é um termo temporal, significando tudo o que esteja acontecendo no presente momento" (DANTO, 2006, p. 12). Danto acredita que por muito tempo o que era chamado de arte contemporânea, nada mais era senão arte moderna sendo feita agora, foi por conta disso que se fez necessário em meados dos anos 1980, a invenção do termo pós-moderno.

Danto nos alerta que "na verdade, o termo pós-moderno de fato pareceu a mim (ele) designar certo estilo que podemos aprender a reconhecer do mesmo modo como aprendemos a reconhecer exemplos do barroco ou do rococó" (DANTO, 2006, p. 14). De acordo com sua perspectiva a arte pós-moderna é parte do contemporâneo, sendo caracterizada pela adoção de elementos híbridos, de certa maneira menos puros, limpos e articulados e muito mais contaminados, ambíguos perversos e interessantes.

Essas características estão presentes nas principais vertentes da sociedade contemporânea e são justamente elas que exigem do observador uma educação estética apropriada. O francês Jacques Ranciére contribui com dois importantes trabalhos para essa discussão: A partilha do sensível (RANCIÈRE, 2009) e O espectador emancipado (RANCIÈRE, 2012). Com esses trabalhos o autor coloca em discussão a importância do observador em comparação a arte, ele trás para o campo da sensibilidade estética o embate

\footnotetext{
${ }^{2}$ Que segundo ele não faz sentido algum, senão for relacionado com o Modernismo. 


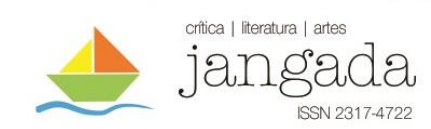

político a cerca dos discursos. E nesse caso, "a política ocupa-se do que se vê e do que se pode dizer sobre o que é visto, de quem tem competência para ver e qualidade para dizer, das propriedades do espaço e dos possíveis do tempo" (RANCIÈRE, 2009, p. 17), para tanto o homem político só poderá compreender e/ou efetuar todo esse processo se ele já estiver emancipado como espectador.

O conceito de espectador emancipado está pautado nessa referência de postura, que "põe a questão do espectador no cerne da discussão entre arte e política" (RANCIÈRE, 2012, p. 08). A proposta de reflexão levantada pelo autor vem sendo construída desde seu livro $O$ mestre ignorante (RANCIÈRE, 2002), com o desenvolvimento da ideia de emancipação intelectual baseada na teoria de Joseph Jacotot, "que causara escândalo no início do século XIX ao afirmar que um ignorante pode ensinar a outro ignorante aquilo que ele mesmo não sabe, ao proclamar a igualdade das inteligências" (RANCIÈRE, 2012, p. 07). Porém, Rancière, fazendo referência ao teatro, lembra que segundo a perspectiva dos acusadores,

É um mal ser espectador, por duas razões. Primeiramente, olhar é o contrário de conhecer. O espectador mantém-se diante de uma aparência ignorando o processo de produção dessa aparência ou a realidade por ela encoberta. Em segundo lugar, é o contrario de agir. O espectador fica imóvel em seu lugar, passivo. Ser espectador é estar separado ao mesmo tempo da capacidade de conhecer e do poder de agir. (RANCIÈRE, 2012, p. 08).

Algumas das novas formas de manifestações da arte contemporânea vêm tentando burlar essa afirmativa e seguindo o exemplo do teatro, desconsiderando a concepção da quarta parede. Rancière fala sobre duas fórmulas empregadas no teatro para a eliminação desse limite imaginário, um funciona a partir da comoção, sendo mostrado para ele "um espetáculo, estranho inabitual, um enigma cujo sentido ele precise buscar. Assim será obrigado a trocar de posição de espectador passivo pela de inquiridor ou experimentador científico que observas os fenômenos e busca suas causas". A outra fórmula pressupõe que é essa própria distância que deve ser abolida, "o espectador deve ser retirado da posição de observador que examina calmamente o espetáculo que lhe é oferecido." (RANCIÈRE, 2012, p. 09). 


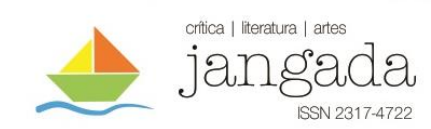

A arte e os artistas contemporâneos já encontraram modos de transmutar essas fórmulas para as outras linguagens artísticas, mas mesmo assim- com tantas performances, vídeos-instalações, happenings e artes interativas- conseguimos identificar outra forma de desleixo. Existe entre os mediadores uma falta de interesse que está aquém do espectador e do artista, uma tendenciosa falta de interesse econômico.

\section{A falta de interesse pelo espaço de exposição}

Todos os pesquisadores têm o dever de reconhecer a importância do mercado para o cenário atual, que existe um interesse de caráter econômico em aquisições exorbitantes por parte de instituições e cada vez mais novos modos de colecionismos emergem entre os membros da sociedade. Um fato noticiado- inclusive abertamente por jornais e mídias populares- trouxe à tona uma questão pertinente, o MASP- Museu de Arte Moderna de São Paulo Assis Chateaubriand com um acervo ${ }^{3}$ estimado entre US\$ 2 bilhões e US\$ 3 bilhões, enfrentou nos últimos anos grandes problemas financeiros e de gestão, ao ponto de ter sua energia elétrica cortada pela empresa distribuidora Eletropaulo.

Segundo informa Dossiê MASP, da Associação Cultural Fórum Permanente, recentemente (24 nov. 2014) o jornal O Estado de São Paulo divulgou a iniciativa de um grupo de empresários em tentar sanar as dívidas mais importantes e dar novo fôlego para a instituição. Segundo consta no texto, o MASP havia acumulado um déficit na casa dos 12 milhões, sendo que "do total da dívida, um quarto era trabalhista, outra igual parte tributária e o restante dividido entre bancos e fornecedores”. (AGÊNCIA ESTADO, 2014).

3 Considerado a maior coleção de arte do Hemisfério Sul. 




Ilustração 3: Vista do MASP. Fonte: MASP.

Recentemente, outra instituição passou por uma situação parecida. O Museu Nacional mantido pela UFRJ- Universidade Federal do Rio de Janeiro teve suas portas fechadas ao público, a alegação é que faltava verba para pagamento de serviços terceirizados, nas áreas de limpeza e segurança. O fato de $20 \%$ do orçamento anual do museu não ter sido liberado pelo MEC para 2014, talvez explique a medida tomada pelos responsáveis em manter durante 14 dias o museu mais antigo do país sem acesso à visitação. Só depois de um pedido- atendido- de adiantamento da verba para 2015 é que a ordem se estabeleceu. 


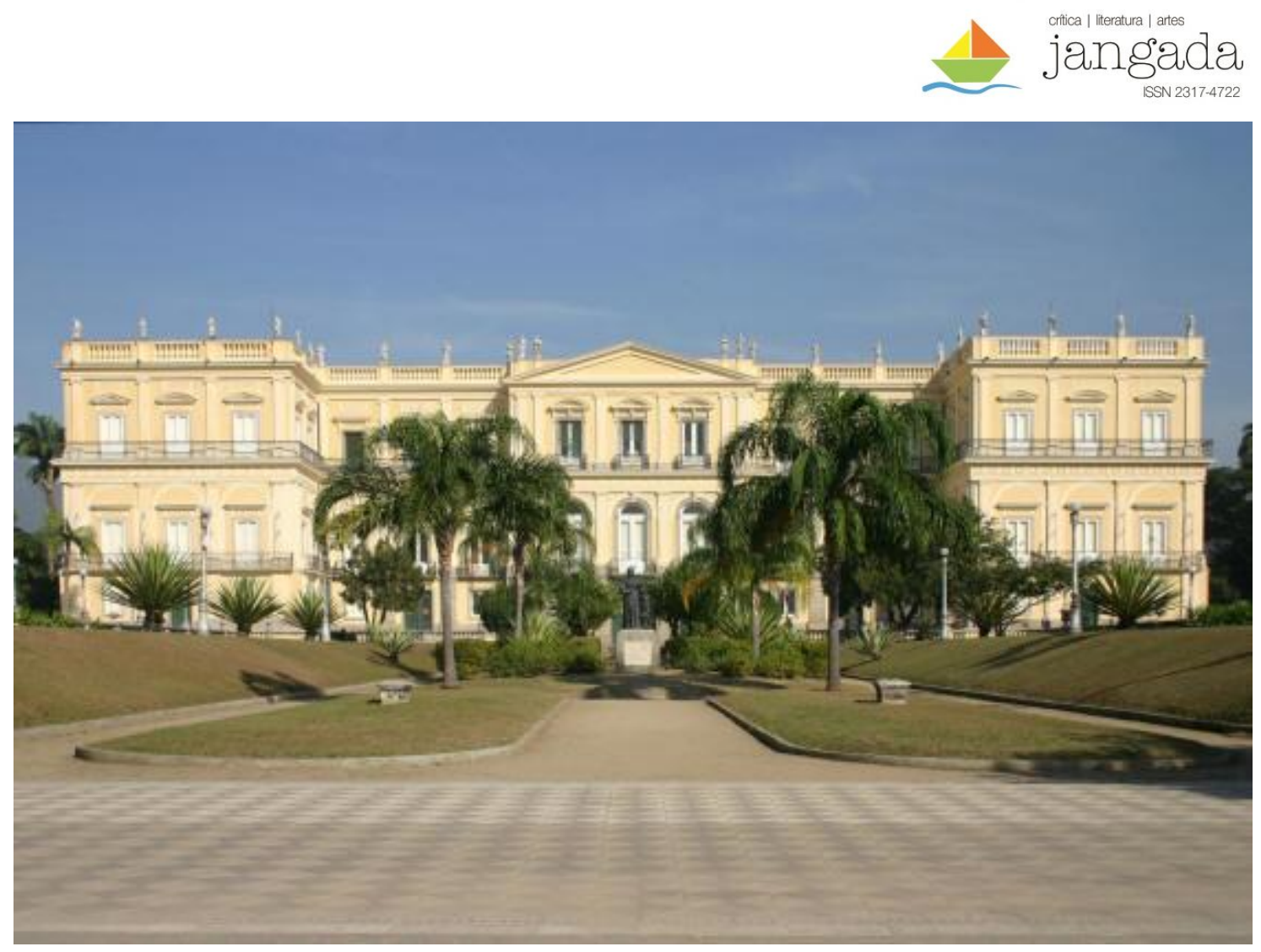

Ilustração 4: Fachada do Museu Nacional. Fonte: Museu Nacional

Esses exemplos, de um museu mantido pela iniciativa privada e outro pela pública, refletem bem o descaso que o campo cultural e artístico se encontra em nosso país. No ano de 2011, o IBRAM- Instituto Brasileiro de Museus publicou o Guia dos Museus Brasileiros, uma espécie de lista de registro, organizada a partir de 2006 com a criação do Cadastro Nacional de Museus. Entre seus conteúdos, distribuídos entre oito tópicos, encontra-se uma tarja amarela que faz referência aos Museus extintos, incorporados $e$ renomeados. Nesse trecho da publicação, que poderia ser chamado de Capítulo VI, visto que é o sexto tópico a ser divulgado encontramos os dados cadastrais e situação dos museus, que por uma causa ou outra tiveram suas portas fechadas para visitação durante o período dos cinco anos de pesquisa. Segundo consta no documento,

Durante o século XX e ainda na atualidade ocorre um expressivo número de extinções de instituições museológicas no País. Em alguns museus, sobretudo nos de natureza administrativa pública, observamos que os acervos e, algumas vezes, os recursos humanos foram transferidos para outras instituições. Em outros casos, não há registro da destinação dada ao acervo. Atualmente esse processo é regulado pelo Estatuto de Museus que, em seu Artigo 8', determina que "a criação, a fusão e a extinção de 


\section{1 jangâda}

museus serão efetivadas por meio de documento público" e, ainda, no Artigo 40, que trata de inventários museológicos e outros registros, especifica em seu parágrafo único: "no caso de extinção dos museus, os seus inventários e registros serão conservados pelo órgão ou entidade sucessora." (IBRAM, 2011. p. 22)

Ao analisar essa parte do documento o leitor encontra 79 museus, sendo que dentre esses apenas um havia sido fechado, mas em compensação 56 foram extintos. Esses dados demonstram a delicada situação que se encontram as instituições museais, mas no mesmo documento existe um contrapeso, das 3.000 instituições cadastradas muitas estavam em processo de implantação e outros 23 já haviam rumado para o ambiente virtual. Acompanhar as novas tendências tecnológicas e rumar para o ambiente digital, parece ser uma ótima opção para as instituições, mas ainda assim, não é garantia de sucesso.

A Lei 8.313/1991, conhecida pelo nome de Lei Rouanet em homenagem ao Ministro da Cultura na época, tem facilitado desde sua instalação a vida de muitos empresários. Com o propósito de converter parte da receita líquida de pessoas físicas e jurídicas a projetos culturais, a lei também serve para incentivar manobras fiscais. Em seu Art. 18, a Lei cita a possibilidade de seus contribuintes poderem deduzir a quantia total ou parcial da doação direto no imposto de renda, conforme alguns critérios. Recentemente essa questão entrou em debate, não por conta da quantia que não é arrecada, cerca de R \$ 2 bilhões por ano, mas por muito dos casos de investimento cultura estar atendendo interesses particulares ${ }^{4}$. Por conta dessa Lei podemos supor que mesmo sendo o desinteresse pela cultura e arte tão grande, haveria um setor onde o interesse cultural persiste, o mercado de arte.

\section{Mercado de arte e a manutenção da ordem especulativa}

Em 2008, as principais nações passaram por uma crise econômica de caráter mundial, afetando vários segmentos da vida cotidiana. No mundo das artes não poderia ser diferente, o diretor Ben Lewis tenta em seu documentário: The Great Contemporary Art Bubble (LEWIS , 2009) compreender e explicar por que depois de cinco anos em alta o

\footnotetext{
${ }^{4}$ Consultar o texto de Leonardo Attuch, na Istoé, indicado na Webgrafia.

Jangada | nr. 10, jul/dez, 2017 | ISSN 2317-4722 - 116 |P á g i n a
} 


\section{1 jangada}

mercado enfrenta um boom nos preços, que consequentemente desestabiliza os investimentos com uma queda posterior de até $50 \%$ nos preços.

Esse caso demonstra não só uma falta de interesse proposital dos mediadores no mercado de arte mundial, mas também de como esse mercado se insere num "jogo" de estratégias, onde o interesse é intercambiado de acordo com fatores externos. Para entender melhor esse processo de circulação de interesses, precisamos compreender o próprio mercado de arte e sua organização, para tanto recorreremos à duas referências, Anne Cauquelin e Alain Quemin.

Cauquelin ao discutir sobre a arte contemporânea organiza um discurso em torno da estrutura que possibilitou seu aparecimento desde a modernidade. Para isso, compara o sistema das artes modernistas e contemporâneas com um regime, e no segundo caso, ao Regime da Comunicação. Ambos- sistemas e regimes- são orientados a partir das seguintes primícias:

Em primeiro lugar, a noção de $\langle<$ rede $>>$ : redes interligadas e metaredes.

Seguem-se: 2/ o looping 5 , ou autonomia; 3/ a redundância, ou saturação da rede; 4/ a nomeação ou prevalência do recipiente (a rede) sobre o conteúdo; 5/ a construção de uma realidade em segundo grau, ou simulação. (CAUQUELIN, 2010, p. 41.)

São esses cinco conceitos alinhados e funcionando normalmente cada qual com sua função que possibilitam a permanência e a manutenção do mercado. Sendo que, a rede corresponde ao funcionamento do sistema, com características dependentes e expansionistas, é ligada a outros canais tecnológicos permitindo a circulação das informações e produtos ${ }^{6}$. O looping é a própria circulação da rede, a impossibilidade de se destacar do sistema, a possibilidade de reversibilidade. A redundância ou saturação da rede é a consequência do looping, a válvula de escape que indica o momento de sair de cena. A denominação, por sua vez, funciona como remédio para os efeitos da saturação, é conceito aplicado para diferenciar aquilo que está sendo feito a partir de uma identidade, de uma particularidade. Por fim, a construção da realidade é uma referência à linguagem

\footnotetext{
${ }^{5}$ Referência à topologia da rede, cujos componentes são conectados em rede de tal forma que o último componente é ligado ao primeiro componente.

${ }^{6}$ Nesse caso obras de arte, artistas, ideia, conhecimentos etc.
} 


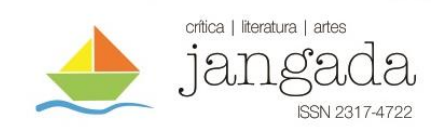

empregada na rede que pouco se importa coma distinção entre verdade e falsidade, esse último conceito serve principalmente para construir um mecanismo de apreensão de outro mundo das artes, ofuscando do senso comum o funcionamento desse mundo real.

Na descrição de Quemin, o mercado da arte também acompanha todas essas características conceituais apontadas por Cauquelin, mas o autor espanhol trás uma análise importante sobre os dois principais segmentos do mercado de arte, um que afeta o valor estético e outro o financeiro. Nesse sentido o grande problema do mercado de arte contemporâneo é desvendar o real valor de uma arte consagrada como contemporânea, deixando a mercê de uma dada "academia informal" à atividade de classificação desses valores, o que obviamente deixa de lado um grande número de outras produções plásticas atuais (QUEMIN, 2014, p.13).

Esse "deixar de lado" é um ato temporal e estratégico, afinal não dá para se valorizar tudo e ao mesmo tempo manter o sistema das artes funcionando. Por conta disso ele fala em uma divisão mais ampla do mercado, entre o de arte antiga e o atual, de arte contemporânea. "Sobre o primeiro, os valores tanto estratégicos quanto financeiros estão amplamente estabilizados, ainda que as mudanças de gosto e a moda possam afetar as reputações e os preços." Porém, no segundo caso, a questão estética é financeira, sendo intercambiadao pela intima relação entre o mercado e o museu, "a certificação do valor estético condiciona o preço, ainda que o preço seja, por sua vez, um dos critérios de certificação do valor estético” (QUEMIN, 2014, p.13)

Sendo assim, a exemplo da crise de 2008, é compreensível que se conclua ao menos que para o circuito de arte, a falta de interesse é "um mal presente que vem para um bem futuro", ou seja, não se deve atribuir valor hoje para aquilo que não se espera adquirir ainda mais valor amanhã.

\section{Considerações finais}

Jangada | nr. 10, jul/dez, 2017 | ISSN 2317-4722 - 118 |P á g i n a 


\section{1 jangada}

Embora as evidências obriguem a aceitar que exista atualmente uma grande falta de interesse pelas Artes, em seus mais variados setores, não podemos de maneira alguma declarar que isso tenha sido suficientemente capaz de declarar o "fim da Arte". Essa é um conceito muito usado por filósofos, críticos e historiadores da Arte para se referirem justamente para o período ao qual estamos inseridos hoje, mas a maioria deles concorda que o fato de a Arte ter chegado a um fim não significa que se tenha deixado de se fazer Arte. Devemos encarar esse fim da arte como nos propõe Arthur Danto, como o fim de uma narrativa.

O grande problema é que essa nova narrativa que veio substituir a antiga exige dos espectadores, dos mediadores, das instituições museais e de mercado uma postura, uma atividade reflexiva complexa que poderá ou não ser tendenciosa. Talvez por conta dessa particularidade envolvendo a contrapartida do indivíduo é que múltiplas interpretações surjam, agradando alguns e frustrando outros. A solução está na educação artística? No estimulo financeiro? Na criação de exposições interessantes? Naqueles que coletam os dados?

Difícil de encontrar a resposta, ao mesmo tempo em que um estudo publicado em 2014 demonstra a falta de interesse dos brasileiros em "qualquer tipo de prática cultural", no ano seguinte outro levantamento mostra que o Brasil teve sete dentre as vinte exposições mais visitadas do mundo no ano de 2014. O Centro Cultural do Banco do Brasil (CCBBs) é a instituição que ganhou mais destaque nessa lista, com seis das sete exposições, sendo que cinco delas aconteceram no Rio de Janeiro e uma em Brasília. A outra exposição aconteceu em São Paulo, no Instituto Tomie Ohtake, mas se ampliarmos a consulta para as 100 mais, encontraremos ainda: o Museu Oscar Niemeyer (PR), o Museu de Arte Moderna de São Paulo e a Pinacoteca do Estado (SP), o Museu do Conjunto Cultural da República (DF) e unidades da Caixa Cultural (IBRAM, 2015). 



Ilustração 5: Detalhes de duas dentre as sete exposições brasileiras (Coleção Ludwig/CCBB São Paulo e Yayoi Kusama/CCBB Rio de Janeiro, respectivamente) entre as mais visitadas em 2014. Fonte: IBRAM.

Esses dados, porém, não podem ser considerados animadores em vista que em sua maioria as exposições a qual se referem tratam de artistas estrangeiros já falecidos, fato que geralmente enobrece a instituição, e que consequentemente seduz os investidores. No documento onde os dados sobre as principais exposições do mundo são comparadas, os especialista advertem o possível fim do chamado boom brasileiro, estimulado principalmente pela estabilidade da economia desde a crise de 2008.

A preocupação dos responsáveis pela The Art Newspaper é que com o eventual e acentuado declínio da economia no Brasil desde os meses finais de 2014, se comprometam as grandes exposições já programas, como a inaugurada no CCBB- São Paulo, que recebeu entre 25 de março e 8 de junho, a exposição "Picasso e a Modernidade Espanhola", sobre o conhecido pintor e de outros artistas modernistas espanhóis, A mesma exposição teve programação agendada para ocorrer no Rio de Janeiro, nos 24 de junho a 7 de setembro.

Outras importantes exposições internacionais forão montadas para o ano de 2015, como por exemplo, Wassily Kandinsky e Juan Miró. Porém, só depois dos próximos levantamentos da instituição britânica é que será possível confirmar se realmente não passava de um boom passageiro que encontrou seu fim. Assim saberemos identificar se finalmente o país está vivenciando um novo começo para a educação estética em todos seus segmentos e classes historicamente marcados pelo desinteresse cultural. 


\section{REFERÊNCIAS BIBLIOGRÁFICAS}

ARGAN, Giulio Carlo. História da arte como história da cidade. - $6^{\mathrm{a}}$ ed.- São Paulo: Martins Fontes- selo Martins, 2014.

. Arte Moderna. São Paulo: Companhia das Letras, 1992.

BELL, Julian. Uma nova história da arte. São Paulo: WMF Martins Fontes, 2008.

CAUQUELLIN, Anne. Arte contemporânea. Mem Martins: Europa- America PT, 2010.

(Coleção Saber).

DANTO, Arthur. Após o fim da arte: a arte contemporânea e os limites da história. São

Paulo: Odysseus Editora, 2006.

GOMBRICH, Ernest. A história da arte. Rio de Janeiro: LTC, 2013. (Livro de Bolso). Arte e ilusão: um estudo da psicologia da representação artística. São Paulo:

WMF Martins Fontes, 2007.

GULLAR, Ferreira. Arte contemporânea brasileira. São Paulo: Lazuli Editora Companhia Editora Nacional, 2012.

IBRAM- Instituto Brasileiro de Museus. Guia dos Museus Brasileiros. Brasília: Instituto Brasileiro de Museus, 2011.

LEIVA, João. Cultura SP: Hábitos culturais dos paulistas. São Paulo Tuva Editora, 2014.

MAMMI, Lorenzo. O que resta da arte. São Paulo: Cia das Letras, 2012.

QUEMIM, Alain. Evolução do mercado de arte: internacionalização crescente e desenvolvimento da arte contemporânea. In: MORAES, Angélica de; FIALHO, Ana Letícia; QUEMIN, Alain. O valor da obra de arte. São Paulo: Metalivros, 2014.

RANCIËRE, Jacques. $O$ espectador emancipado. São Paulo: Editora WMF Martins Fontes, 2012.

- A partilha do sensível: estética e política. - $2^{\mathrm{a}}$ ed.- São Paulo: EXO experimental org.; Editora 34, 2009.

$O$ mestre ignorante: cinco lições sobre a emancipação intelectual. Belo Horizonte: Autêntica Editora, 2002.

SANTAELLA, Lúcia. Culturas e artes do pós-humano: da cultura das mídias à cibercultura. São Paulo: Paulus, 2003.

\section{Videografia}

LEWIS, Ben. The Great Contemporary Art Bubble. Reino Unido: Ben Lewis TV Company, 2009. Disponível em: https://distrify.com/films/6542 Acesso em 01 mai. 2015. MESQUITA, Marcelo; VALIENGO, Guilherme. Cidade cinza. Brasil: Bretz Filmes, 2013.

WALKER, Lucy. Lixo extraordinário. Reino Unido, Brasil: Almega Projects;

O2 Filmes, 2009.

\section{Webgrafia}

ATTUCH, Leonardo. Nos estertores da Lei Rouanet: Além da renúncia fiscal, o governo gasta mais de R \$ 300 milhões ao ano para subsidiar interesses privados. In: ISTOÉ INDEPENDENTE. Istoé colunista. Disponível em: http://www.istoe.com.br/colunas-eblogs/coluna/423617_NOS+ESTERTORES+DA+LEI+ROUANET - Acesso em: 21 jun. 2015. 


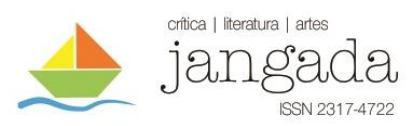

AGÊNCIA ESTADO. Empresários se unem e arrecadam R\$ 15 milhões para resgatar o MASP. Publicado em 24 nov. 2014, apud FORUM PERMANENTE. Dossiê MASP. Disponível em http://www.forumpermanente.org/imprensa/dossie-masp/empresarios-seunem-e-arrecadam-r-15-milhoes-para-resgatar-o-masp Acesso em 18 abr. 2015. [a] Dossiê MASP. Disponível em

http://www.forumpermanente.org/imprensa/dossie-masp Acesso em 18 abr. 2015. [b] IBRAM- Instituto Brasileiro de Museus. Notícias- Mostra e Exposições: Exposições brasileiras estão entre as 20 mais visitadas no mundo em 2014- Publicado em 07 abr. 2015. Brasília: Instituto Brasileiro de Museus, 2015. Disponível em https://www.museus.gov.br/exposicoes-brasileiras-estao-entre-as-20-mais-visitadas-nomundo-em-2014/ Acesso em 05 jun. 2015.

PRESIDÊNCIA DA REPÚBLICA. Lei $n^{\circ}$ 8.313, de 23 de dezembro de 1991. Disponível em: http://www.planalto.gov.br/ccivil_03/leis/L8313cons.htm Acesso em: 21 jun. 2015.

SESC-SEGIPE (Serviço Social do Comércio - Departamento Regional de Sergipe). Mais Notícias: Pesquisa inédita revela hábitos culturais do brasileiro. 09/04/14 - 16h29. Disponível em: http://www.sesc-se.com.br/noticias/752-pesquisa-inedita-revela-habitosculturais-do-brasileiro Acesso em 18 abr. 2015.

THE ART NEWSPAPER. Special Report: number 267, April 2015. Disponível em: http://www.museus.gov.br/wpcontent/uploads/2015/04/TheArtNewspaper_Ranking2014.pdf Acesso em 05 jun 2015.

\section{Fonte das imagens:}

Ilustração 1: NO QUINTAL DE CASA. A cidade cinza. Publicado em 22 de abr. de 2011. Disponível em: http://nokintaldecasa.blogspot.com.br/2011/04/cidade-cinza.html Acesso em 13 jan. 2017.

Ilustração 2: BLOG DO SADOVSKY. Documentário Cidade Cinza joga novas cores na arte de rua de São Paulo. Publicado em 22 nov. 2013. São Paulo: UOL- Universo On Line S/A, 2013. Disponível em: http://nokintaldecasa.blogspot.com.br/2011/04/cidadecinza.html - Acesso em 13 jan. 2017.

Ilustração 3: MASP- MUSEU DE ARTE MODERNA DE SÃO PAULO ASSIS CHATEUBRIAND. Sobre o MASP. São Paulo:MASP, 2009. Disponível em: http://masp.art.br/masp2010/sobre masp_missao.php Acesso em 13 jan. 2017.

Ilustração 4: MUSEU NACIONAL. Redescobrindo a casa do imperador. Rio de Janeiro: UFRJ, s/d. Disponível em: http://www.museunacional.ufrj.br/casadoimperador/ Acesso em 13 jan. 2017.

Ilustração 5: IBRAM- Instituto Brasileiro de Museus. Notícias- Mostra e Exposições: Exposições brasileiras estão entre as 20 mais visitadas no mundo em 2014- Publicado em 07 abr. 2015. Brasília: Instituto Brasileiro de Museus, 2015. Disponível em https://www.museus.gov.br/exposicoes-brasileiras-estao-entre-as-20-mais-visitadas-nomundo-em-2014/ Acesso em 13 jan. 2017. 